\title{
Modeling and simulation of DC to DC boost converter using single phase matrix converter topology
}

Fajariah Kadir, S.Z. Mohammad Noor, Faranadia A. H., K.S. Muhammad

Faculty of Electrical Engineering, Universiti Teknologi MARA, Malaysia

\begin{tabular}{l}
\hline \hline Article Info \\
\hline Article history: \\
Received Oct 19, 2019 \\
Revised Dec 12, 2019 \\
Accepted Jan 19, 2020 \\
\hline
\end{tabular}

\section{Keywords:}

MATLAB/Simulink

PWM

Single phase matrix converter

\begin{abstract}
The main objective of this work is to model and simulate DC to DC Boost Converter using Single Phase Matrix Converter (SPMC) topology using MATLAB/Simulink (MLS). The output voltage is controlled by using Pulse Width Modulation (PWM) technique. Four pairs of Insulated Gate Bipolar Transistor (IGBT) is used as the switching device where for each pair, it is located in parallel and opposite direction. Safe commutation technique is performed in preventing voltage spike at the output. Through the simulation, at switching frequency of $25 \mathrm{kHz}$, the model is able to step up its input voltage about two times larger and all of the results achieved a good agreement with the principle of four quadrant operation. It is also realized that without the implementation of safe commutation technique, spikes were generated and the model is unable to boost its input voltage. All of the selected results from the analysis which includes variation of quadrant, switching frequency, duty cycle and resistive load are presented in this paper.
\end{abstract}

This is an open access article under the CC BY-SA license.

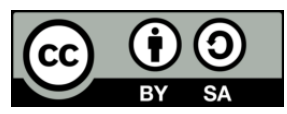

\section{Corresponding Author:}

Fajariah Kadir, Faculty of Electrical Engineering, Universiti Teknologi MARA, 40450 Shah Alam, Selangor.

Email: aja.kadir96@gmail.com

\section{INTRODUCTION}

Single Phase Matrix Converter is applicable in many applications such as for induction heating, AC$\mathrm{AC}$ converter, rectifier, inverter, AC voltage controller, frequency changer (cycloconverter) and dual converter. Dual converter is used for bi-directional speed control of DC drive and DC-DC converter. Every electrical appliance had their own rating. This rating usually displayed on the sticker or rating plate on the electrical appliance. The rating that being displayed actually represents the voltage at which the appliance is designed to operate and the current consumption at that particular voltage. This is where the implementation of power electronics converter is very important such as DC-DC converter, inverter, rectifier and other power converter. A DC power supply is used in most of the appliances where a constant voltage is required. DC-DC power converters are employed in a variety of applications, including power supplies for personal computer, office equipment, spacecraft power system, laptop computer, and telecommunications equipment, as well as DC motor drives [1]. The DC-DC converter is also an important application for alternative electrical power conditioning as for example photovoltaic, wind generator and fuel cell system [2]. There are three common type of DC-DC converter which are; Buck, Boost and Buck Boost Converter.

Matrix Converter (MC) is in fact regarded as an advanced circuit topology which presents countless advantages with unlimited switching control, possible 'all silicon solutions' or with minimum usage of reactive device [3]. It is a forced commutated converter to control or create the variable output voltage across the load by using controlled bi-directional switches with unlimited frequency which actually permits high frequency operation [4]. The topology of MC was actually introduced first by Gyugi in year 1976 [5]. It offers numerous 
advantages including the capability to regenerate energy back to the utility, sinusoidal input and output current and a controllable displacement factor for input current [6]. Matrix Converter obtained substantial interests as it has both topological and operational characteristics in satisfying the present trends of drives [7-10]. It has also enticed the industry application and the technical improvement was further sped up given the powerful demand for energy efficiency, power quality and reducing the size of the converters [11]. In one of the study conducted on MC, it is realized that indirect Matrix Converter (IMC) can be implemented for permanent magnet synchronous motor drive [12]. Despite the fact that Matrix Converter offers many advantages, there are several issues involved in dealing with this converter such as protection issues, current commutation, harmonic and switching losses as well as abnormal input/output voltage [13]. Among these issues, the main problem in engaging with Matrix Converter is said to be the commutation problem which related to the bidirectional switches implementation and hence leads to the occurrence of spike due to the transitions of switching during supplying the inductive load [14]. Therefore, safe commutation strategy need to be implemented in preventing the occurrence of voltage spike. Through a study conducted on Boost Inverter using SPMC topology, it is proven that with the implementation of safe commutation strategy, spikes were successfully eliminated [15]. The single phase version of Matrix Converter is known as Single Phase Matrix Converter (SPMC) which was first realized by Zuckerberger [16]. S.H. Hoseini [17] and Abdullah Khoie [18] have studied the other topologies of SPMC. Since then, more studies on conventional matrix converter have carried on. It is realized that SPMC can be used in many applications such as AC-AC converter, rectifier, DCDC converter, inverter and dual converter [19-20]. A study in 2018 shows that Single Phase Matrix Converter (SPMC) can also be used in induction heating applications as an AC-AC converter implementation [21]. It is also realized that SPMC is capable to act as buck/boost controlled rectifier with reduced switch count [22]. Through a study carried out on grid-to-vehicle (G2V) wireless power transfer using SPMC topology, it is realized that the use of SPMC can directly convert AC to AC, eliminating the complexity of conventional ACDC-AC converter [23]. Currently, there are many research on three phase Matrix Converter nevertheless as for SPMC, although it is an advanced circuit topology, it has only been seen for a very limited or few work.

This paper presents the modeling and simulation of DC to DC Boost Converter using SPMC topology. The primary task of Boost Converter is to produce a controlled output voltage that is higher than the input voltage [24]. The main purpose of this research is to step up the supply voltage by using SPMC topology and this operation can only be simulated in Quadrant 1 and Quadrant 3 only. To support the basic principle of four quadrant operation, operation of DC Chopper in Quadrant 2 and Quadrant 4 using SPMC topology is also discussed in this paper. The circuit is constructed and simulated by using MATLAB/Simulink (MLS) for all four quadrants. The circuit consists of four pairs of IGBTs with opposite directions which acted as the power switching device. The output voltage across the load is synthesized by using Pulse Width Modulation (PWM) technique. As for the load, the load used is resistive load with the implementation of LC filter to eliminate the distortion or ripple on waveform of the output voltage. Output results when safe commutation is implemented in the circuit were presented in this paper.

\section{RESEARCH METHOD} research.

In this section, it will discuss all of the method used in completing and achieving the objectives of this

\subsection{DC to DC boost converter}

Boost converter is used to step up a DC voltage and the arrangement for a Boost converter is as illustrated in Figure 1. The converter will step up the DC voltage from Vs to Vo. When the switch, denoted as sw, or often known as chopper is closed, the inductor current increases and the energy is stored in the inductor, L. This process is called the inductor's charging process. When the switch, sw is opened, the energy that had been stored in the inductor will be transferred via diode D1 to the load and causes the inductor current to drop. This process is actually discharging process of the inductor. The switch can be bipolar junction transistor (BJT), insulated-gate bipolar transistor (IGBT), and others [25]. DC to DC Boost converter is used widely in regulated DC power supplies, regenerative braking of DC motors, portable device applications etc. The average output voltage for a DC to DC Boost Converter is as shown in (1) where D is the duty cycle of the switch's opening and closing. The value of duty cycle may vary between 0 to 1 .

$$
V_{O}=V S\left(\frac{1}{1-D}\right)
$$




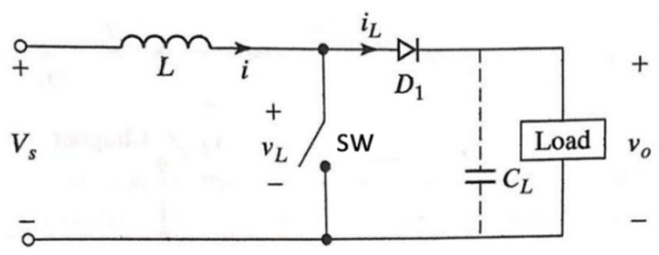

Figure 1. DC to DC boost converter arrangement

\subsection{Single phase matrix converter}

Basically, SPMC composed of four bidirectional switches as shown in Figure 2, basic operation of four quadrant as shown in Figure 3 Four bidirectional switches are required so that it is able to block voltage and conduct current in both directions. Nonetheless, there is no discrete semiconductor device for bidirectional switches and anti-parallel IGBT is therefore used. In SPMC, the implementation of safe commutation switching strategies is very important to prevent switching spike phenomenon due to the usage of practical devices [26].

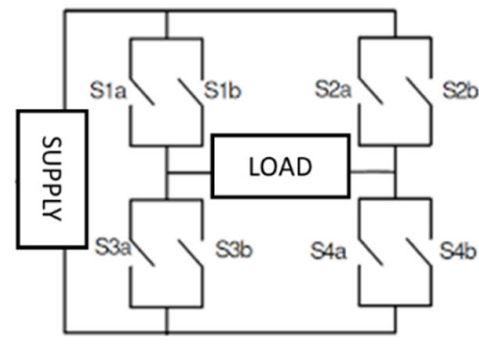

Figure 2. Basic single phase matrix converter topology

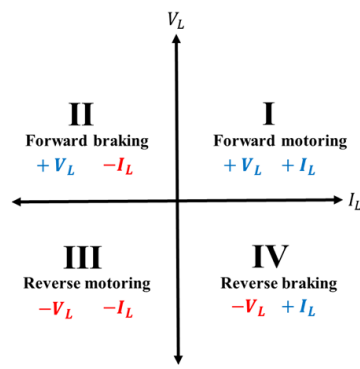

Figure 3. Basic operation of four quadrant

\subsection{Proposed DC to DC boost converter using SPMC topology}

The proposed DC to DC Boost converter using SPMC topology as depicted in Figure 4 used four pair of insulated-gate bipolar transistor (IGBT) which is located anti parallel to each other for every pairs. IGBTs are selected as the switching devices due to its high switching frequency and its capability of handling high current which leads to application of medium power such as power supplies, contractors, solid state relays, motor drives etc. A sole IGBT can handle a current rating up to $6500 \mathrm{~V}, 2400 \mathrm{~A}$ while can be up to $20 \mathrm{kHz}$ as for the switching frequency [27]. Besides, IGBT also has a low on state power dissipation. The inductor in the circuit acted as the boost inductor which will be charging during the switch is on and discharge its energy to the load when the switch is off. The output voltage across the load is synthesized or controlled by implementing Pulse Width Modulation (PWM) technique.

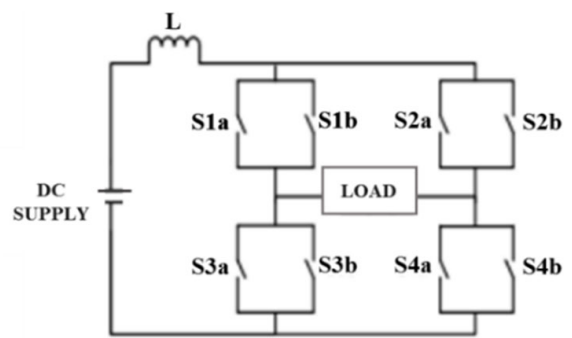

Figure 4. DC to DC boost converter using spmc topology 


\subsubsection{Pulse width modulation (PWM)}

The load voltage or output voltage across the load for the DC to DC Boost converter using SPMC topology is controlled by employing PWM technique. This particular technique is implemented by comparing a triangular wave signal; the carrier signal, and a constant adjustable DC signal; the reference signal. As a result, the switching pulse duty cycle could be varied to synthesize the required DC to DC Boost converter. The triangular wave signal or carrier signal can be either " $\mathrm{M}$ " shape or "W" shape. By employing PWM technique, a series of pulse train is generated to turn on and off the switching device [28] as depicted in Figure 5 . The switch will be on when the reference signal is greater than the carrier signal and will be off when the reference signal is less than the carrier signal.

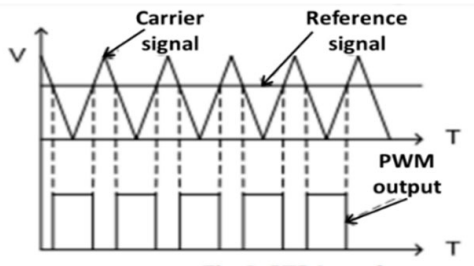

Figure 5. Pulse width modulation (PWM)

\subsubsection{Commutation problem}

There is a serious problem when dealing with matrix converter, which is the occurrence of spike due to the transitions of switching during supplying the inductive load [14]. In SPMC, the sequence of switching should be instantaneous and simultaneously, which impossible practically, caused by the turn "on" and "off" time within the characteristics of the IGBT. When the switch that controlled the voltage across load, synthesized using PWM is turned "on", the inductor is charged and the energy is stored in the inductor. During turn "off", this is where the commutation problem arises when the energy stored in the inductor is transferred to the load. Therefore, a safe commutation need to be implemented in providing "way" for the current to flow to the load so that the energy stored in the inductor is able to be transferred to load during "off" state. Figure 6 shows the summary for the operation for each switch during the four quadrants operation, switching Strategies as shown in Table 1.

Table 1. Switching Strategies

\begin{tabular}{ccccc}
\hline Switch & Quadrant 1 & Quadrant 2 & Quadrant 3 & Quadrant 4 \\
\hline S1a & On & Off & PWM & Off \\
S1b & Off & On & Off & Off \\
S2a & Off & Off & On & Off \\
S2b & Off & Off & Off & On \\
S3a & PWM & PWM & On & Off \\
S3b & On & Off & Off & On \\
S4a & On & Off & Off & PWM \\
S4b & Off & On & On & Off \\
\hline
\end{tabular}

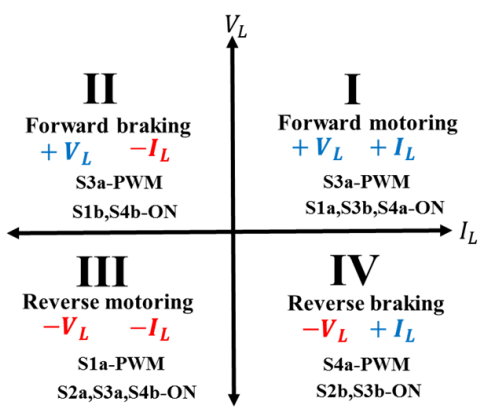

Figure 6. Four quadrant operation using SPMC 


\section{i. First quadrant (Q1)}

For the operation of the first quadrant which is forward motoring, both load voltage, $\mathrm{V}_{\mathrm{L}}$ and load current, $\mathrm{I}_{\mathrm{L}}$ are positive. The load current flows out of the source to the inductor and in order to achieve this condition, switch S1a, S3b, S4a are set "on" while switch S3a employs PWM technique to control the charging and discharging of the inductor. Charging of inductor during quadrant 1 operation (S3a PWM - On) and Discharging Of Inductor During Quadrant 1 Operation (S3a PWM- Off) are shown in Figure 7 and Figure 8.

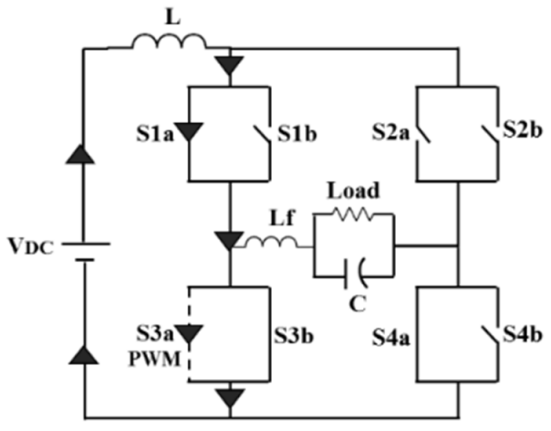

Figure 7. Charging of inductor during quadrant 1 operation (S3a PWM - On)

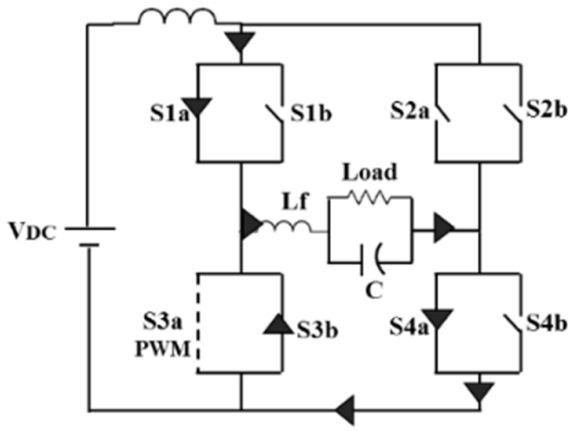

Figure 8. Discharging Of Inductor During Quadrant 1 Operation (S3a PWM- Off)

\section{ii. Second quadrant (Q2)}

Quadrant 2 is forward braking, where the load will become supply, driven by voltage E which is battery. In this quadrant, it is impossible to simulate a DC to DC Boost converter. Therefore, for this particular quadrant, it will only perform the operation of DC Chopper in Quadrant 2. During this quadrant, the load voltage will be positive. As for the load current, its magnitude will be negative and flows out from the load. In achieving this condition, switch S3a employs PWM technique whereas switch S1b and S4b are set as continuously on. The current through the load will be driven by another supply, battery E. When switch S3a is off, the load dissipated its energy via S1b and S4b to the DC supply, Current driven by e through load during quadrant 2 operation (S3a PWM - On) shown in Figure 9. VDC as depicted in Figure 10.

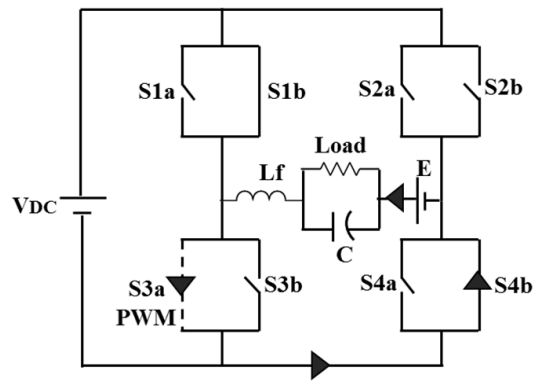

Figure 9. Current driven by e through load during quadrant 2 operation (S3a PWM - On)

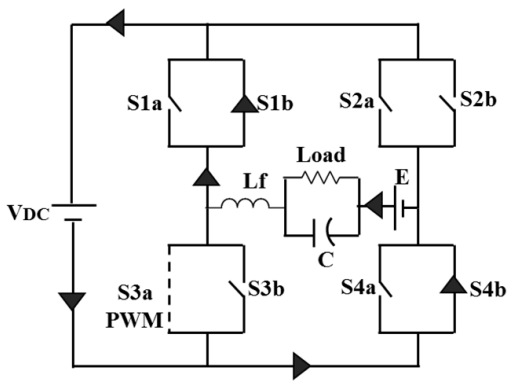

Figure 10. Energy dissipated to the supply during quadrant 2 operation (S3a PWM- Off)

\section{iii. Third quadrant (Q3)}

Magnitude of both load voltage and current are negative. The operation of this quadrant is known as reverse motoring. The load current flows by using different route from the supply to the load. This condition is achieved by setting switch S1a to PWM control whereas S2a, S3a, S4b are set as continuously on. When $\mathrm{S} 1 \mathrm{a}$ is on, the current will flow from load, driven by E to the inductor; charging the inductor. When switch S1a is off, the energy stored in the inductor will be transferred to the load; discharging of inductor. The flow of current when switch S1a is on and off are illustrated in Figure 11 and Figure 12 respectively. 


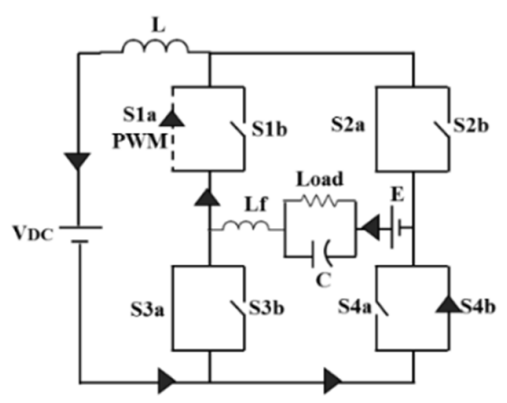

Figure 11. Charging of inductor during quadrant 3 operation (S1a PWM - On)

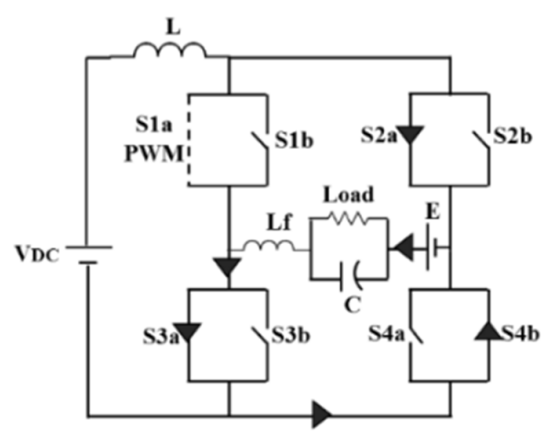

Figure 12. Discharging of inductor to the load during quadrant 3 operation (S1a PWM- Off)

\section{iv. Fourth quadrant (Q4)}

The fourth quadrant is a reverse braking quadrant where the load voltage is negative in magnitude whereas the load current is positive. The load will act as supply while supply will act as load. The load current flows out of the load. For this quadrant, the simulation of DC to DC Boost converter is impossible and hence will only simulate the operation of DC Chopper for quadrant four. In achieving this condition, switch S4a utilizes PWM technique whereas switch S2b and S3b are set to continuously on. When switch S4a is on, current across the load will be driven by battery E and during S4a is off, load dissipated its energy to the supply as shown in Figure 13 and Figure 14.

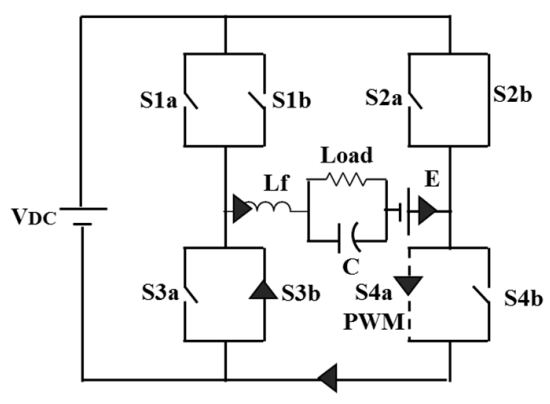

Figure 13. Current driven by e through load during quadrant 4 operation (S4a PWM - On)

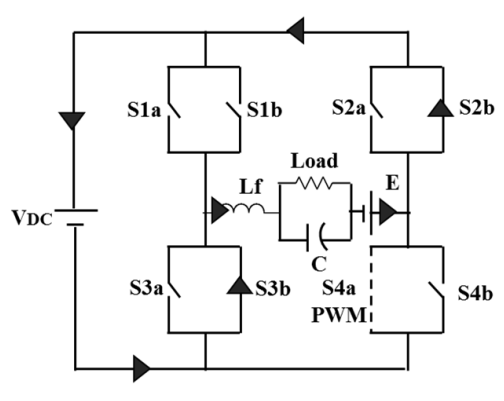

Figure 14. Energy dissipated to the supply during quadrant 4 operation (S4a PWM- Off)

\subsection{Simulation model}

The circuit is modeled and simulated by using MLS. The circuits were supplied by a DC voltage source with amplitude of $20 \mathrm{~V}$; the load is a pure resistive load, $\mathrm{R}$ which is $20 \Omega$; boost inductor of $3 \mathrm{mH}$. LC filter is implemented in the circuit as to reduce output voltage ripple; $\mathrm{L}=3 \mathrm{mH}, \mathrm{C}=5 \mathrm{nF}$. For operation for Quadrant 2,3 and 4, DC supply, E represent back emf of DC motor of 5V. All of the parameters used in the simulation model is summarized as in Table 2. The simulation model of PWM switching control is as depicted in Figure 15. It is obtained by comparing a triangular wave carrier signal and a constant DC reference signal. Figure 16, 17, 18 and 19 shows the simulation model for Quadrant 1, 2, 3 and 4 respectively using MLS. The switching strategies are different for each quadrant, depending on its operation required output.

Table 2. Parameters used for simulation

\begin{tabular}{ll}
\hline \multicolumn{1}{c}{ Component } & Value \\
\hline Supply voltage, $\mathrm{V}_{\text {in }}$ & $20 \mathrm{~V}$ \\
Boost inductor, L & $4 \mathrm{mH}$ \\
Output resistor, R & $20 \Omega$ \\
Battery, E & $5 \mathrm{~V}$ \\
\hline
\end{tabular}




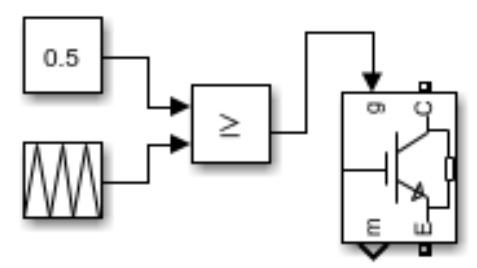

Figure 15. PWM control model

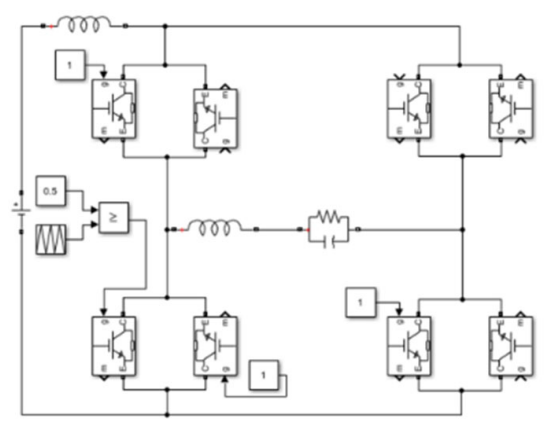

Figure 16. Simulation model using MLS for DC to DC boost converter using SPMC (Quadrant 1)

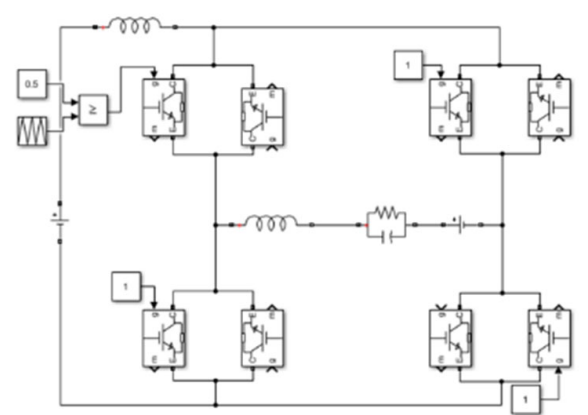

Figure 18. Simulation model using MLS for DC to DC boost converter using SPMC (Quadrant 3)

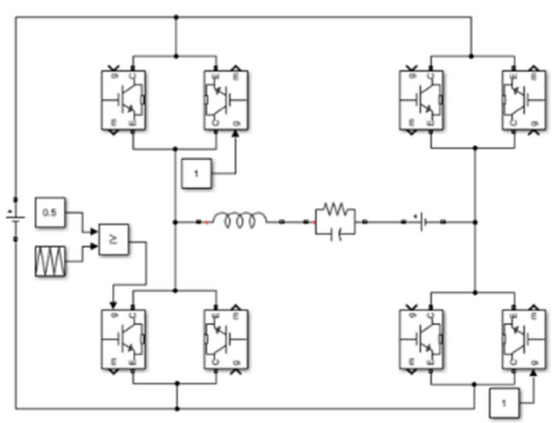

Figure 17. Simulation model using MLS for DC converter using SPMC (Quadrant 2)

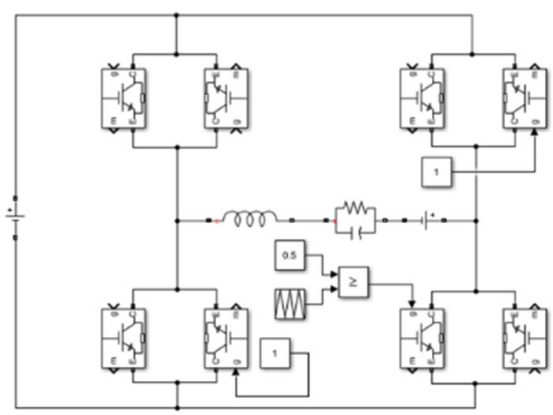

Figure 19. Simulation model using MLS for DC converter using SPMC (Quadrant 4)

\section{RESULTS AND ANALYSIS}

Simulation of the model was done by using MLS. Figure 20 to Figure 27 showed the results of output voltage and output current for each quadrant with switching frequency, fs of $25 \mathrm{kHz}$ and duty cycle, $\mathrm{m}_{\mathrm{a}}$ of 0.5 . Table 3 shows the summary of the value output voltage current for every quadrant at this condition. From Table 3 , the results obtained for output voltage and output current for each quadrant, followed the basic four quadrant operation as shown in Figure 3. As for the operation of DC to DC Boost Converter using SPMC topology in Quadrant 1 and Quadrant 3, the model simulated using MLS are able to boost its input voltage about 2 times. 


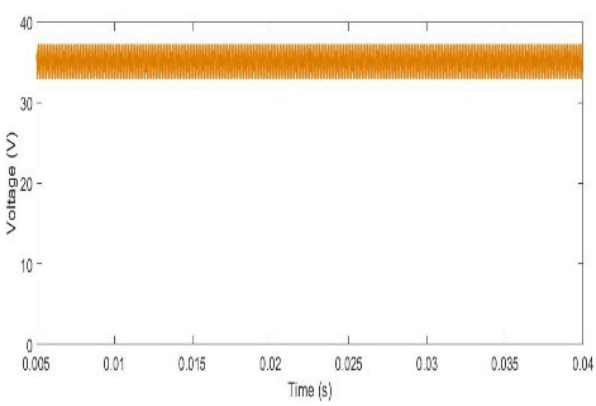

Figure 20. Output voltage for quadrant 1 , $\mathrm{Vin}=20 \mathrm{~V}, \mathrm{Vmean}=35.1 \mathrm{~V}$

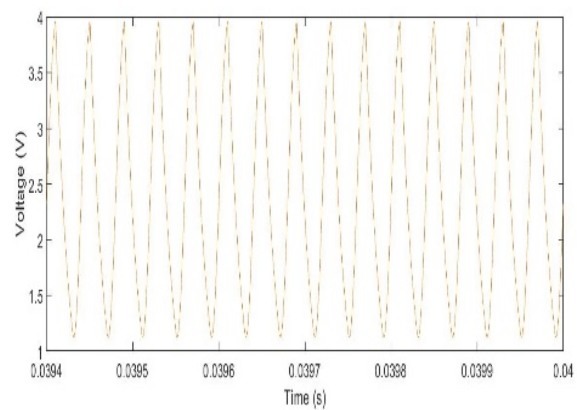

Figure 22. Output voltage for quadrant 2, Vin $=20 \mathrm{~V}$, Vout $=2.363 \mathrm{~V}$

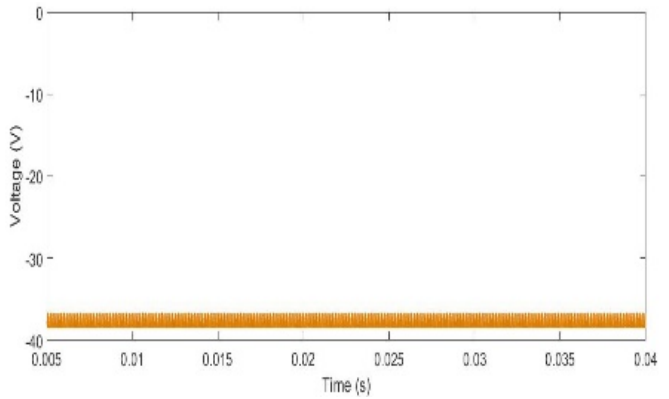

Figure 24. Output voltage for quadrant 3, Vin $=20 \mathrm{~V}$, Vmean $=-38 \mathrm{~V}$

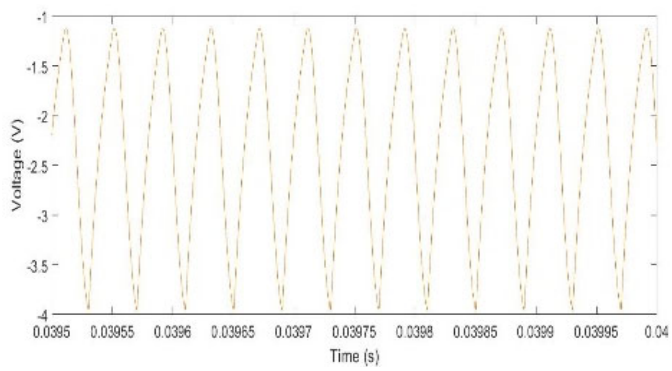

Figure 26. Output voltage for quadrant 4, Vin $=20 \mathrm{~V}$, Vout $=-2.363 \mathrm{~V}$

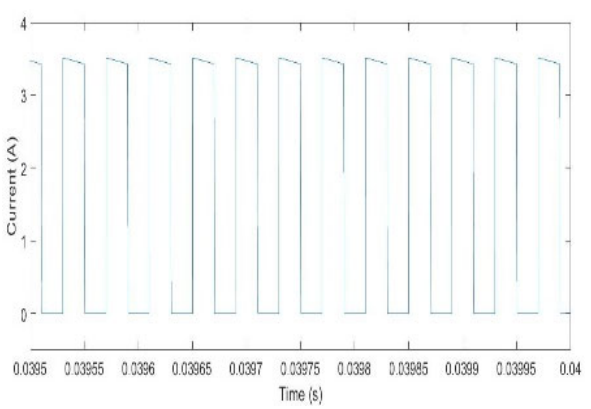

Figure 21. Output current for quadrant 1, Iout $=1.755 \mathrm{~A}$

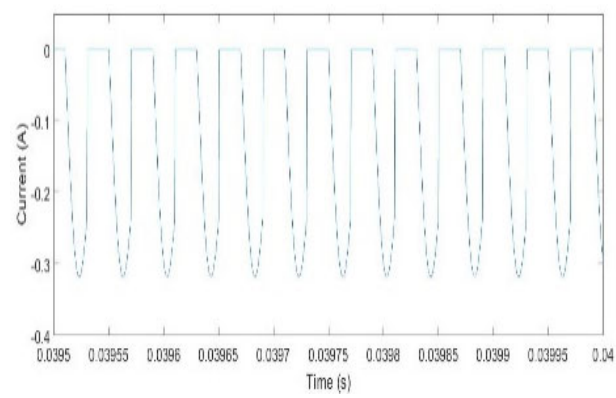

Figure 23. Output current for quadrant 2, Iout $=-0.1181 \mathrm{~A}$

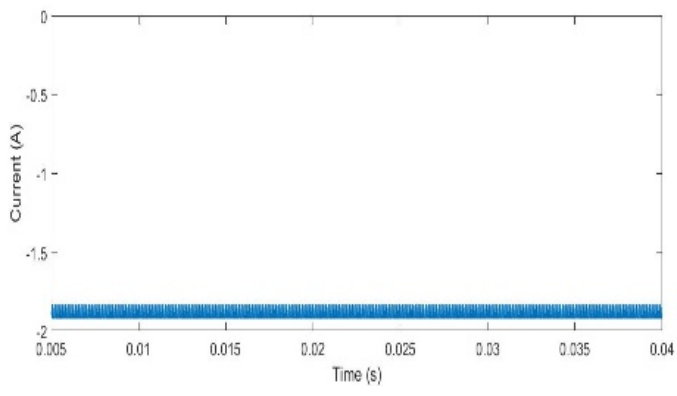

Figure 25. Output current for quadrant 3, Iout $=-1.9 \mathrm{~A}$

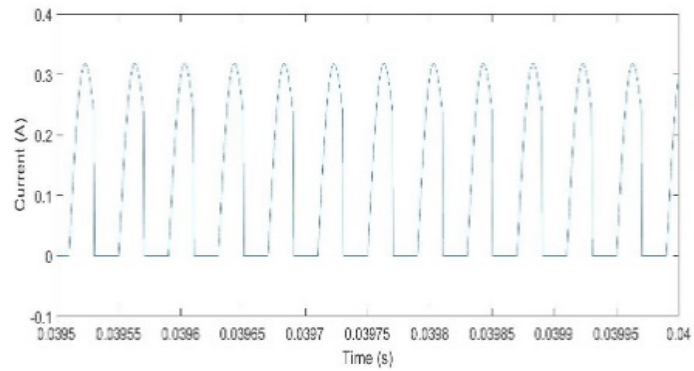

Figure 27. Output current for quadrant 4 , Iout $=0.1181 \mathrm{~A}$ 


\begin{tabular}{|c|c|c|}
\hline & $\mathrm{V}_{\text {out }}(\mathrm{V})$ & $\mathrm{I}_{\text {out }}(\mathrm{A})$ \\
\hline Quadrant 1 & 35.1 & 1.755 \\
\hline Quadrant 2 & 2.363 & -0.1181 \\
\hline Quadrant 3 & -38 & -1.9 \\
\hline Quadrant 4 & -2.363 & 0.1181 \\
\hline
\end{tabular}

\subsection{Varying switching frequency, $\mathrm{f}_{\mathrm{s}}$}

To analyze the performance of DC to DC Boost Converter using SPMC, the switching frequency are varied for five sets of value which are $5 \mathrm{kHz}, 10 \mathrm{kHz}, 15 \mathrm{kHz}, 25 \mathrm{kHz}$ and $50 \mathrm{kHz}$. The duty cycle, $\mathrm{m}_{\mathrm{a}}$ is $\mathrm{kept}$ constant at 0.5 . Figure 28 and Figure 29 shows the waveform of output voltage for DC to DC Boost Converter using SMPC in Quadrant 1 at switching frequency of $5 \mathrm{kHz}$ and $50 \mathrm{kHz}$ accordingly. The duty cycle ma is kept constant at 0.5. From Figure 28 and Figure 29, it is observed that as switching frequency is increased, the waveform of output voltage become smoother. With increase of switching frequency, it will result in decrease of voltage ripple at the output since the charging and discharging times of the inductor become significantly shorter with an increase in switching frequency.

\subsection{Varying duty cycle, $m_{a}$}

Table 4 summarized the value of output voltage, Vout obtained through simulation of DC to DC Boost Converter using SPMC topology in Quadrant 1 and Quadrant 3. It is observed that as the duty cycle is increased, the output voltage is also increased for both quadrants. Using the formula for average output voltage of Boost Converter as shown in (1), with an increase of the duty cycle, the average output voltage will increase too. As the duty cycle is increased, the time for the switch synthesized by PWM to on will also increase, resulting in longer charging time. Therefore, the energy stored in the inductor will increase. However, it is not applicable to Quadrant 3 operation because of its reverse motoring property; the output voltage will remain constant.

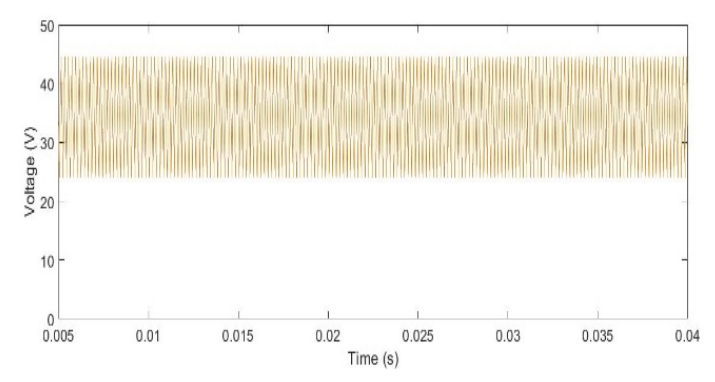

Figure 28. Waveform of output voltage for boost converter using SPMC in quadrant 1 , vmean = $34.56 \mathrm{~V}$ at $5 \mathrm{kHz}$

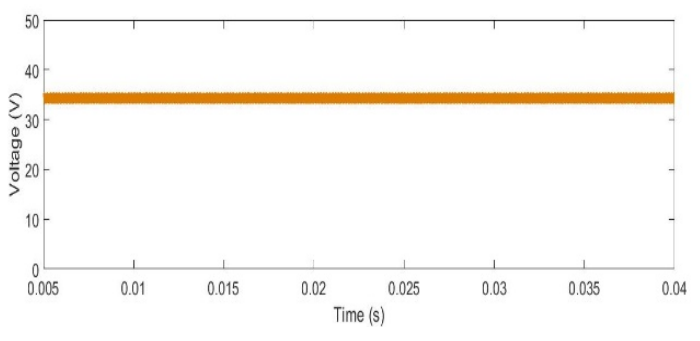

Figure 29. Waveform of output voltage for boost converter using SPMC in quadrant 1 , vmean $=$ $34.33 \mathrm{~V}$ at $50 \mathrm{kHz}$

Table 4. Average output voltage for quadrant 1 and quadrant 3 with respect to ma

\begin{tabular}{ccc}
\hline Duty cycle, $\mathrm{m}_{\mathrm{a}}$ & \multicolumn{2}{c}{ Average output voltage, $\mathrm{V}_{\text {mean }}(\mathrm{V})$} \\
Quadrant 1 & Quadrant 3 \\
\hline 0.5 & 35.1 & -38 \\
0.6 & 43.29 & -38 \\
0.7 & 56.17 & -38 \\
0.8 & 78.39 & -38 \\
0.9 & 111.1 & -38 \\
\hline
\end{tabular}

\section{CONCLUSION}

The method in modelling and simulating the DC to DC Boost Converter using SPMC topology by using MATLAB/Simulink (MLS) has been outlined. For Quadrant 2 and Quadrant 4, a model of DC Chopper for the respective quadrants had been presented. The simulation results achieve good agreement with the theory of four quadrant operation. For DC to DC Boost Converter using SPMC topology, through the simulation, the results showed that the model implemented able to boost it input voltage for about two times larger at switching 
frequency of $25 \mathrm{kHz}$. Other parameters had been varied to study on its effect to the output voltage. The selected simulation results showed that DC to DC Boost Converter using SPMC topology can be implemented for practical use. DC to DC Boost Converter is widely been used in power electronic appliances such as power supplies etc.

\section{ACKNOWLEDGEMENTS}

This research is supported by the Fundamental Research Grant Scheme (FRGS) (FRGS/1/2017/TK04/UITM/03/13) from the Ministry of Education Malaysia (MOE).

\section{REFERENCES}

[1] R. W. Erickson, "DC-DC Power Converters," in Wiley Encyclopedia of Electrical and Electronics Engineering, 2007.

[2] W. I. Hameed, B. A. Sawadi, and A. Muayed, "Voltage Tracking Control of DC- DC Boost Converter Using Fuzzy Neural Network," International Journal of Power Electronics and Drive Systems (IJPEDS), vol. 9, no. 4, pp. 1657$1665,2018$.

[3] S. Z. M. Noor, N. F. A. Rahman, and M. K. Hamzah, "Simulation of DC to DC converter using single phase matrix converter topology," ISIEA 2010 - 2010 IEEE Symposium on Industrial Electronics and Applications (ISIEA), pp. 149-154, 2010. pp. 149-154, 2010.

[4] P. W. Wheeler, J. Rodríguez, J. C. Clare, L. Empringham, and A. Weinstein, "Matrix converters: A technology review," IEEE Transactions on industrial electronics, vol. 49, no. 2, pp. 276-288, 2002.

[5] L. Gyugyi and B. R. Pelly, "Static Power Chargers, Theory, Performance and Application," John Wiley \& Son Inc, 1976.

[6] S. Chawda, D. Ahirrao, B. Gaware, P. Kakade, and P. Kharade, "Analysis of Single Phase Matrix Converter," International Journal of Engineering Research and Applications www.ijera.com ISSN, vol. 4, no. 1, pp. 856-861, 2014

[7] M. Venturini, "New Sine Wave in, Sine Wave Out Conversion Technique Eliminates Reactive Elements.," Proceedings Powercon 7, pp E3_1-E3_15, 1980.

[8] D. Borojević, "Space Vector Modulated Three-Phase to Three-Phase Matrix Converter with Input Power Factor Correction," IEEE transactions on industry applications, 1995.

[9] F. Abrahamsen et al., "List of Contributors," in Control in Power Electronics, 2002.

[10] S. Kwak, "Indirect matrix converter drives for unity displacement factor and minimum switching losses," Electric Power Systems Research, 2007.

[11] A. Roth-Deblon, "Combined DC and AC integration of energy sources in hybrid 3-phase off-grid systems," Conference Record of the 2006 IEEE 4th World Conference on Photovoltaic Energy Conversion, WCPEC-4, vol. 2, no. 1, pp. 2431-2433, 2007.

[12] A. M. Nori and T. K. Hassan, "Modeling and simulation of quasi-Z-source indirect matrix converter for permanent magnet synchronous motor drive," International Journal of Power Electronics and Drive Systems (IJPEDS), vol. 10, no. 2, pp. 882-899, 2019.

[13] R. Ghoni, A. N. Abdalla, S. P. Koh, H. F. Rashag, and R. Razali, "Issues of matrix converters: Technical review," International Journal of Physical Sciences, vol. 6, no. 15, pp. 3628-3640, 2011.

[14] R. Baharom and M. K. Hamzah, "A new single-phase controlled rectifier using single-phase matrix converter topology incorporating active power filter," in Proceedings of IEEE International Electric Machines and Drives Conference, IEMDC 2007, 2007.

[15] M. F. Mohd Zin, R. Baharom, and I. Mohd Yassin, "Development of boost inverter using single phase matrix converter topology," International Journal of Engineering \& Technology, vol. 7, no. 4, pp. 241-245, 2018.

[16] A. Zuckerberger, D. Weinstock, and A. Alexandrovitz, "Single-phase matrix converter," IEE Proceedings-Electric Power Applications, 2002.

[17] S. H. Hosseini and E. Babaei, "A new generalized direct matrix converter," in IEEE International Symposium on Industrial Electronics, 2001.

[18] A. Khoei and S. Yuvarajan, "Single-Phase AC-AC Converters Using Power Mosfet's," IEEE Transactions on Industrial Electronics, vol. 35, no. 3, pp. 442-443, 1988.

[19] M. Vorobyov, "Overview of Single Phase Matrix Converter Application," Publication of Doctoral School of Energy and Geotechnology, vol. 3, pp. 201-207, 2011.

[20] K. Vijayakumar, R. S. Raj, and S. Kannan, "Realization of Matrix converter as revolutionized power electronic converter employing sinusoidal pulse width modulation," in 2013 IEEE International Conference on Computational Intelligence and Computing Research, IEEE ICCIC 2013, 2013.

[21] R. Kumar, S. Srivastava, S. P. Singh, and N. Singh, "Simulation of matrix converter based DC-DC converter," 2013 Students Conference on Engineering and Systems, SCES 2013, pp. 134-138, 2013.

[22] R. M. Anusuya and R. Saravanakumar, "Modeling and Simulation of a Single Phase Matrix Converter with Reduce Switch Count as a Buck / Boost Rectifier with Close Loop Control," Special Issue of IJCET, pp. 93-99, 2015.

[23] M. Q. I. M. Zamani, R. Baharom, and D. Johari, "Conceptual study on grid-to-vehicle (G2V) wireless power transfer using single-phase matrix converter," International Journal of Power Electronics and Drive Systems (IJPEDS), vol. 10 , no. 3, pp. $1382-1388,2019$.

[24] J. G. Kassakian, M. F. Schlecht, and G. C. Verghese, Principles of power electronics, Graphis, 2000. 
[25] S. D. Mitchell, S. M. Ncube, T. G. Owen, and M. H. Rashid, "Applications and market analysis of DC-DC converters," in Proceedings of ICECE 2008 - 5th International Conference on Electrical and Computer Engineering, 2008.

[26] Z. Yu, A. Mohammed, and I. Panahi, "A review of three PWM techniques," In Proceedings of the 1997 American Control Conference (Cat. No. 97CH36041), vol. 1, pp. 257-261. IEEE, 1997.

[27] Muhammad H.Rashid, Power Electronics Devices, Circuits and Applications, Fourth Edition Pearson, 2014.

[28] S. Z. M. Noor, R. Baharom, M. K. Hamzah, and N. R. Hamzah, "Safe-commutation strategy for controlled rectifier operation using singlephase matrix converter," in Proceedings of the International Conference on Power Electronics and Drive Systems, 2009.

\section{BIOGRAPHIES OF AUTHORS}
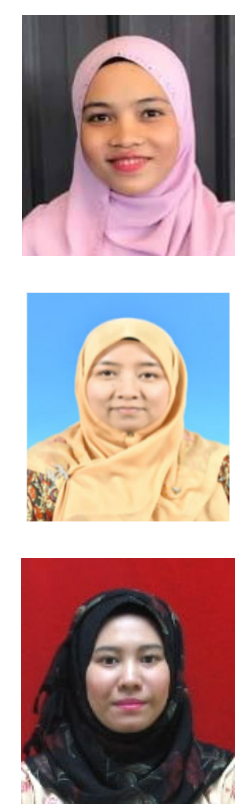

Fajariah Binti Kadir obtained Bachelor of Electrical Engineering in 2019 from Universiti Teknologi Mara (UiTM). She wrote this journal in accordance to her final year project which based on her research and simulation results. She is currently seeking for a platform in the field of engineering to establish her career and to utilize her abilities. Her current research interests include power electronics, semiconductor devices, circuit modeling and simulation.

Dr. Siti Zaliha Binti Mohammad Noor obtained Bachelor of Electrical Engineering (Hons) in 2005, MSc Power Electronics in 2008 and $\mathrm{PhD}$ in Electrical Engineering in 2018 from Universiti Teknologi MARA (UiTM), Malaysia. She is currently a Senior Lecturer at the Faculty of Electrical Engineering, UiTM. She has authored and co-authored over 30 technical papers in indexed international journal and conferences. Her research interests are renewable energy, power electronics, modeling and simulation, signal processing and embedded controller applications.

Faranadia Bt Abdul Haris is a lecturer at the Faculty of Electrical Engineering, Universiti Teknologi MARA. She received her Bachelor of Science in Electrical System Engineering at the Faculty of Electrical Engineering, Universiti Malaysia Perlis (UniMAP). She was supported by Young Lecturer Scholarship of University Teknologi MARA (UiTM) and Kementerian Pendidikan Tinggi Malaysia (KPT) during MSc Electrical Engineering from 2013-2015. 